\title{
Florid granulomatous reaction in a seminoma
}

\author{
W. RUSSELL PICKARD* $\ddagger$ \\ M.B., F.R.C.S. (Glas)
}

\author{
Alistair H. ClarK \\ M.B., Ch.B., D.R.C.O.G.
}

\author{
B. J. ABEL* \\ M.B., F.R.C.S. (Edin) \\ Departments of *Urology and †Pathology, Victoria Infirmary, Glasgow G42 $9 T Y$
}

\begin{abstract}
Summary
A case of seminoma of the testis complicated by an extensive granulomatous reaction is reported. This reaction was so florid that a benign condition was initially considered until further material for histology was examined and the correct diagnosis made.
\end{abstract}

KEY WORDS: granulomatous reaction, seminoma.

\section{Introduction}

A granulomatous reaction in a seminoma is a fairly common occurrence; a mild or patchy granulomatous reaction being present in $30 \%$ of classical seminomas and a severe reaction in 10\% (Thackray and Crone, 1976).

A case is reported in which this reaction was much more marked than in any previous reports, being so extensive that initially a diagnosis of granulomatous orchitis was considered on histological examination.

\section{Case report}

A 26-year-old single male presented with a 4 week history of painless swelling of the right testis. On examination there was a mass involving the right testis which was non-tender and did not transilluminate. A diagnosis of testicular tumour was suspected and orchidectomy was performed via an inguinal incision.

The testis measured $70 \times 45 \times 40 \mathrm{~mm}$. and, on section, a sharp line of demarcation was present between the tumour and a rim of normal testicular tissue. Multiple blocks of the testis were examined histologically and, in many blocks, the appearance seemed typical of a granulomatous orchitis, with multiple granulomas, several Langhans type giant cells and a diffuse lymphocytic infiltrate. However, in

$\ddagger$ Present address: University Department of Surgery, Western Infirmary, Glasgow G11 6NT other blocks, tiny islands of seminoma cells were interspersed between the granulomas (Fig. 1). This 8 granulomatous response was seen throughout the tumour-involved area but was not apparent in the $\omega$ uninvolved pole of the testis, although a mild ${ }_{0}^{+}$ lymphocytic infiltrate was seen round a few tubules. $\triangle$

Human chorionic gonadotrophin was undetected $\vec{z}$ in the serum sampled postoperatively and the alpha fetoprotein concentration was normal.

Chest X-ray, lymphangiogram, computerised to $\bar{\oplus}$ mographic scan, ultrasound and liver scan were 11 c. normal. A sperm count revealed severe oligoospes 뭉 mia. He has since received radiotherapy 3500 rads his scrotum, inguinal and para-aortic glands and remains well.

\section{Discussion}

A marked granulomatous reaction occurs in some areas in $10 \%$ of seminomas but is always said to have a patchy distribution (Thackray and Crone, 1976). 하 However, this case showed a florid reaction involving the entire tumour-related area, a reaction that ex- 윽 ceeds that in any case previously recorded in the testicular tumour registry (Pugh R.C.B.-personal communication). Such a histological finding poses a problem in distinguishing between a very severe윽 granulomatous reaction in a seminoma and a semi- $\rightarrow$ noma arising in a pre-existing granulomatous orchi- 을 tis. A pre-existing granulomatous orchitis can prob- N ably be excluded in this case on the following grounds: that there is absence of the characteristic 0 inflammation of the tunica vaginalis (Morgan, 1976) and that there is no evidence of thickening of the tunica albuginea (Lynch, Eakins and Morrison, $c$ 1968). In addition, there appeared to be a normal rim $\Phi$ of testis uninvolved by a granulomatous reaction. $\stackrel{?}{?}$ There has been, in fact, no report of seminoma $\square$ complicating granulomatous orchitis.

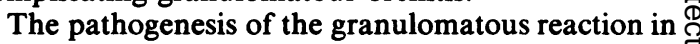




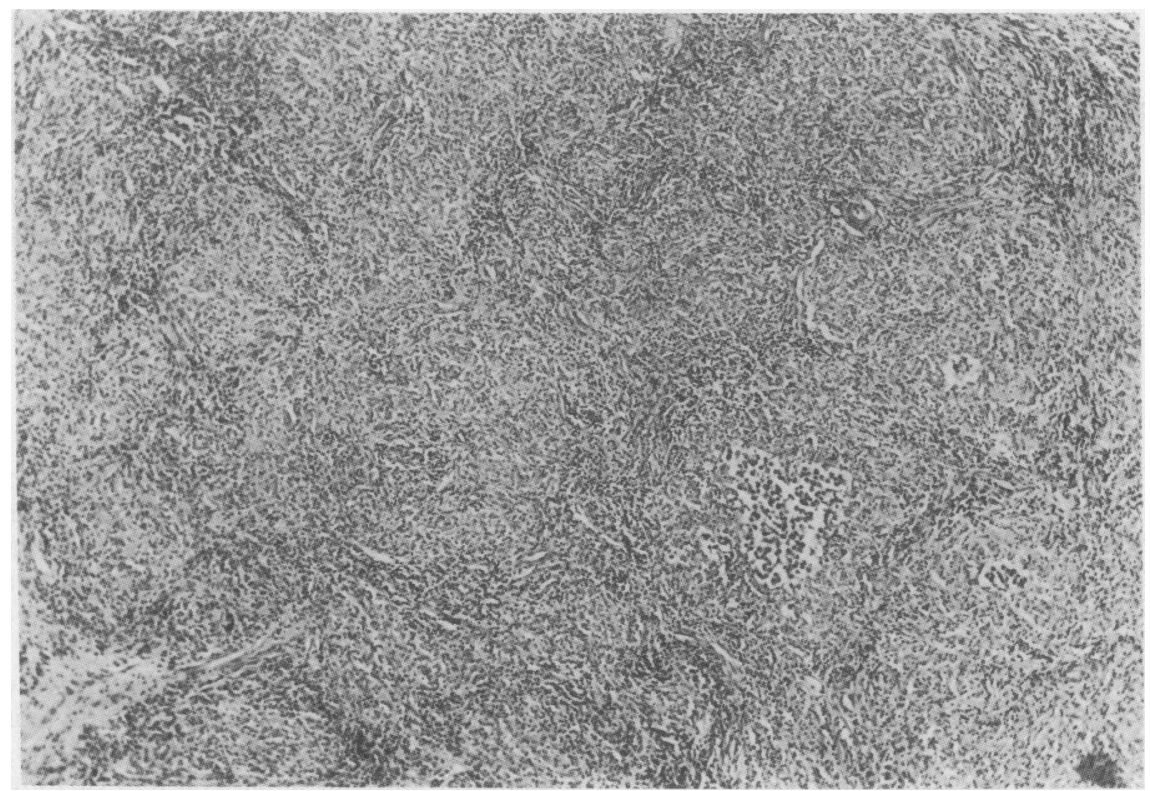

FIG. 1. Islands of seminoma cells interspersed between granulomas $($ H.E., $\times 40)$.

a seminoma may be analogous to the reaction to normal sperm found in granulomatous orchitis. It has been suggested that dying seminoma cells, by liberating lipid from the cytoplasm, elicit a granulomatous response (Thackray, 1978). However, in all previous cases, the reaction has been patchy in distribution and has involved only one lobule of the tumour. It is clearly important that several blocks of the lesion be examined in such cases to obtain the correct diagnosis. In addition, other causes of granuloma formation, notably tuberculosis, should be excluded.

The presence of a pronounced granulomatous response confers a good prognosis, in that cases where the response is marked show a $10 \%$ increased survival at 5 years compared with those with no granulomatous response (Thackray and Crone, 1976).

The clinical features of both seminoma and granulomatous orchitis can be similar in that testicular swelling is the commonest presenting symptom in both disorders and there is a considerable overlap in the age of presentation. In one series of cases of granulomatous orchitis, the age range was 26 to 72 years (Lynch et al., 1968). Of the 17 cases of seminoma seen in this department since 1973, the age range varied between 27 to 68 years; of these cases only 2 showed a granulomatous response.

In conclusion, this case is presented to alert pathologists and clinicians of the potential diagnostic trap of florid granulomatous reaction in a seminoma.

\section{Acknowledgment}

We are grateful to Dr H. M. McCallum for her helpful comments.

\section{References}

LYNCH, V.P., EAKINS, D. \& MORRISON, E. (1968) Granulomatous orchitis. British Journal of Urology, 40, 451.

Morgan, A.D. (1976) In: Pathology of the Testes, p. 111. Blackwell Scientific Publications, Oxford.

Thackray, A.C. (1978) In: Systemic Pathology. 2nd edn, Vol. 14, Ch. 26. Churchill Livingstone, Edinburgh.

ThaCKRAY, A.C. \& CRONE, W.A.J. (1976) In: Pathology of the Testes, p. 164. Blackwell Scientific Publications, Oxford.

(Accepted 25 August 1982) 